\title{
Development of a Predictor Model for Quality of Life in Cancer Patients with Adverse Drug Reactions due to Cancer Chemotherapy
}

\author{
Smita Khandelwal ${ }^{1}$, Laxminarayana Kurady Bairy ${ }^{2 *}$, M. S.Vidyasagar ${ }^{3}$, Asha Kamath ${ }^{4}$, James Gonsalves ${ }^{5}$, \\ Bharti Chogtu ${ }^{2}$ \\ ${ }^{1}$ Department of Pharmacology, Melaka Manipal Medical College (Manipal campus), Manipal University, Manipal, India. ${ }^{2}$ Department of Pharmacology, \\ Kasturba Medical College, Manipal University, Manipal, India. ${ }^{3}$ Department of Radiotherapy and Oncology, Kasturba Medical College, Manipal \\ University, Manipal, India. ${ }^{4}$ Department of Community Medicine, Kasturba Medical College, Manipal University, Manipal, India. ${ }^{5}$ Department of \\ Physiology, Melaka Manipal Medical College (Manipal campus), Manipal University, Manipal, India.
}

\begin{tabular}{l} 
ARTICLE INFO \\
\hline Article history: \\
Received on: 07/01/2016 \\
Revised on: 04/03/2016 \\
Accepted on: 15/04/2016 \\
Available online: $28 / 05 / 2016$ \\
\hline Key words: \\
Quality of life, \\
Chemotherapy, Tertiary care \\
hospital, Multivariate \\
regression, Predictor model.
\end{tabular}

\begin{abstract}
Cancer is one of the leading causes of morbidity and mortality worldwide. There are various detrimental symptoms experienced by a cancer patient due to the disease and the undergoing treatment which adversely affects the Quality of Life (QOL) in these patients. Therefore, QOL and its evaluation have turned out to be progressively vital in the health care system. Hence, the aim of our study was to develop a predictor model to predict the QOL in cancer patients receiving chemotherapy. The study was carried out in the Department of Radiotherapy and Oncology, Kasturba hospital, Manipal, a tertiary care hospital. Predictor model was developed to predict the Quality of Life Scores (QOLS) using multivariate regression analysis. A total of 387 patients participated in the study. Mean age of the patients was $50.85 \pm 11.82$ years $(95 \%$ CI, 49.66-52.03). In our study, $16.54 \%$ had poor global health status/QOL, $72.35 \%$ had average and $11.11 \%$ had a high global health status/QOL. A significant difference was found in the QOLS based on the age group, site of cancer, drugs used in treatment of cancer, age as a predisposing factor and organ system affected due to ADRs (respiratory system, sensory system, skin and appendages). In the predictor model, the Coefficient of determination $\mathrm{R}$-square $\left(\mathrm{R}^{2}\right)$ was found to be 0.3267 indicating that $32.67 \%$ of the variation in the 'quality of life score' is explained by the independent variables included in the model. The $\mathrm{F}_{(45,341)}=3.67, \mathrm{p}<0.001$ indicating the overall significance of the regression model. Thus, the study showed that there are various predictors that can assess the QOL in cancer patients which can further serve as a guide to implement timely interventions to improve patients QOL.
\end{abstract}

\section{INTRODUCTION}

Cancer is one of the leading causes of morbidity and mortality worldwide. More than $60 \%$ of world's total new annual cases of cancer occur in Africa, Asia and Central and South America. These regions account for $70 \%$ of the world's cancer deaths (Cancer Report, 2014). Cancer prevalence in India has been estimated to be around 2.0 to 2.5 million, with over 7-8 lakh new cases detected every year and 4-5 lakh cancer deaths per year (Project Proposal, 2012). Cancer outcomes are traditionally

\footnotetext{
* Corresponding Author

Dr. KL Bairy, Professor, Department of Pharmacology, Kasturba Medical College, Manipal, Karnataka (India)Telephone: 0820-2922365 Email:kl.bairy@manipal.edu
}

measured in terms of overall survival, disease free survival, time to disease progression and other disease variables. Although these outcomes remain essential, there is a general recognition of the need to assess the impact of cancer and its treatment on patient's health-related quality of life (HR-QOL) (Chaukar et al., I2005). WHO defines Quality of Life (QOL) as individual's perception of their position in life in the context of the culture and value systems in which they live and in relation to their goals, expectations, standards and concerns. It is a broad ranging concept affected in a complex way by the person's physical health, psychological state, level of independence, social relationships, personal beliefs and their relationship to salient features of their environment (WHO QOL, 1997). The financial burden due to cancer is an important issue of concern for the purchasers and payers. 
Adverse Drug Reactions (ADRs) are the basic reason for hospitalization and prompts huge expenses to society. As most ADRs never come to clinical attention, the expenses of hospitalization seems as a part of the total costs (Lundkvist and Jonsson, 2004). ADR related morbidity and mortality have been estimated at US\$ 30 billion to US\$ 130 billion annually (Johnson and Bootman, 1995). There are various detrimental symptoms experienced by a cancer patient due to the disease and the undergoing treatment which adversely affect the QOL in these patients. Hence, QOL and its evaluation have turn out to be progressively vital in the health care system (Guyatt et al., I1993). With this background, the aim of our study was to develop a predictor model to predict the QOL in cancer patients who developed ADRs due to cancer chemotherapy.

\section{MATERIALS AND METHODS}

The study was carried out in the Department of Radiotherapy and Oncology, Kasturba hospital, Manipal which is a tertiary care multidisciplinary teaching hospital, provides both inpatient and outpatient healthcare services in all specialties. The study was carried out for a duration of 3 years (October 2011 to September 2014) and included 387 patients who developed ADRs due to cancer chemotherapy. Patients of either sex, age above 18 years and starting cancer chemotherapy in Kasturba Hospital, Manipal were included in the study. The study was approved by institutional ethics committee (IEC 169/2011). Patients willing to participate were explained about the study and an informed written consent was obtained from each patient.

Patients admitted in the cancer wards were followed prospectively during their hospital stay. Baseline information comprising of demographic data like age, gender of the patient, disease and treatment variables were collected from the patient's record. Investigator went through the patient records including the case sheets, laboratory reports and prescription charts to monitor for the ADRs and the details were documented in the patient profile form. The total (direct and indirect) cost incurred by the patient due to ADRs was calculated. Length of stay of the patients in the hospital due to ADRs were assessed.

QOL was measured using standard European Organisation for the Research and Treatment of Cancer QLQ-C30 (EORTC QLQ-C30) version 3. Patients were requested to fill the QOL questionnaire during the mid-cycle of cancer chemotherapy. The questionnaire was provided in a language that the patient could understand (English/ Kannada/ Malayalam). EORTC QLQC30 is a well-known instrument for measuring QOL in cancer patients and is composed of both multi-item scales and single-item measures.

These included five functional scales (physical, role, emotional, cognitive and social), three symptom scales (fatigue, nausea and vomiting, pain), six single items (dyspnoea, insomnia, appetite loss, constipation, diarrhoea and financial difficulties) and a global health status / QOL scale (Aaronson et al., I1993; Fayers et al., I2001). To develop a predictor model for the Quality of
Life Scores (QOLS), various independent variables used in this study included the age group and gender of the patient, site of cancer, onset of reaction, severity and preventability of ADRs, drugs causing ADRs, comorbid conditions, polypharmacy, age as a predisposing factor, organ system (blood, Cardiovascular System (CVS) Central Nervous System (CNS), Peripheral Nervous System (PNS), gastrointestinal, musculoskeletal, renal, respiratory and sensory system, skin and appendages) affected due to ADRs, length of stay of patient in hospital due to ADRs and total cost due to ADRs.

\section{Statistical analysis}

Data was analyzed using descriptive statistics and results were expressed in percentage, mean and standard deviation (SD). Mean with $95 \%$ confidence interval (CI) was used to summarize the age of patients. Mann-Whitney $U$ test was done to find the significance of QOLS with all the independent variables in the study.

After scoring the data, predictor model was developed to predict the QOLS using multivariate regression analysis. Values of $\mathrm{p}<0.05$ were considered to be statistically significant. All analyses were performed using SPSS version 15.

\section{RESULTS}

A total number of 387 patients who developed 582 ADRs participated in the study with a mean age $50.85 \pm 11.82$ years (95\% CI, 49.66-52.03).

Table 1 shows the demographic characteristics of the patients and type of cancer.

Table 1: Demographic characteristics of patients and type of cancer, $\mathrm{n}=387$.

\begin{tabular}{ccc}
\hline \multicolumn{1}{c}{ Characteristics } & No. of Patients, n (\%) \\
\hline Gender & $171 \quad(44.19)$ \\
Male & $216 \quad(55.81)$ \\
Female & $74 \quad(19.12)$ \\
Age group (years) & $230(59.43)$ \\
$21-40$ & $81 \quad(20.93)$ \\
$41-60$ & $2 \quad(0.52)$ \\
$61-80$ & & \\
$>80$ & 93 & $(24.0)$ \\
Type of cancer & 50 & $(12.90)$ \\
Gastrointestinal & 96 & $(24.80)$ \\
Genitourinary & 69 & $(17.80)$ \\
Breast & $42(10.90)$ \\
Lung & $9(2.30)$ \\
Head \& Neck & $14 \quad(3.60)$ \\
Thyroid & $6(1.60)$ \\
Lymphoma and leukaemia & $4(1.0)$ \\
Myeloma & 4 & $(1.0)$ \\
Bone &
\end{tabular}

The patients who participated in this study were on various drug/drug combinations. Most commonly used individual drugs were cisplatin, capecitabine and paclitaxel. Of the drug combinations, paclitaxel + carboplatin and doxorubicin + cyclophosphamide were most frequently used. 
Most of the reported ADRs (524) had latent onset followed by 41 which were sub-acute and only 17 had an acute onset of reaction. Severity of ADRs were assessed using Hartwig scale (Hartwig et al., I1992). In our study, moderate (level 3) type reaction was the most observed followed by mild (level 1) and mild (level 2). Moderate (level 4a, 4b) and severe (level 5) were less observed and there were no severe (level 6) ADRs. 23 ADRs (severe level 7) lead to the death of the patient.

Based on modified Schumock and Thornton, it was found that most of the ADRs were not preventable (470), some were probably preventable (107) and very few were definitely preventable (5) (Schumock and Thornton, 1992). It was found that 126 patients were on polypharmacy, 101 had comorbid conditions and 83 patients were above 60 years of age. In some patients, more than one predisposing factors were observed.

Patients on cisplatin reported highest no. of ADRs followed by capecitabine and paclitaxel. Of the drug combinations, patients on paclitaxel + carboplatin showed highest no. of ADRs followed by doxorubicin + cyclophosphamide. Commonly affected organ systems due to ADRs were blood, skin and appendages, gastrointestinal system, CNS and PNS.

Out of 387 patients, 51 were admitted to the hospital due to ADR/ADRs. The mean increase in length of stay of patients in hospital due to ADRs was found to be 12.5 days. The total cost due to ADRs in cancer patients on chemotherapy in our study was found to be INR $39,72,737(\approx 62,568 \mathrm{US} \$$; 1 US\$ $=63.49$ $I N R)$.

Table 2 represents the global health status/QOL in cancer patients with ADRs on chemotherapy. The scores ranging from 0$33.33,33.34-66.66$ and 66.67-100 represents poor, average and high QOLS. In our study, $16.54 \%$ had poor global health status/QOL, $72.35 \%$ had average and $11.11 \%$ had a high global health status/QOL.

Table 2: Global health status/ Quality of Life in cancer patients with ADRs on chemotherapy, $\mathrm{n}=387$

\begin{tabular}{ccc}
\hline QOL Scores & Frequency & Percent \\
\hline 0 & 15 & 3.9 \\
8.33 & 3 & 0.8 \\
16.66 & 42 & 10.9 \\
25 & 4 & 1 \\
33.33 & 73 & 18.9 \\
41.66 & 18 & 4.7 \\
50 & 110 & 28.4 \\
58.33 & 11 & 2.8 \\
66.66 & 68 & 17.6 \\
75 & 6 & 1.6 \\
83.33 & 34 & 8.8 \\
91.66 & 1 & 0.3 \\
100 & 2 & 0.5 \\
Total & 387 & 100 \\
\hline
\end{tabular}

\section{Relation between quality of life scores and independent variables}

In our study, significant differences were found in the QOLS based on age group, site of cancer, drugs used in treatment of cancer, age as a predisposing factor and organ system affected due to ADRs (respiratory system, sensory system, skin and appendages).

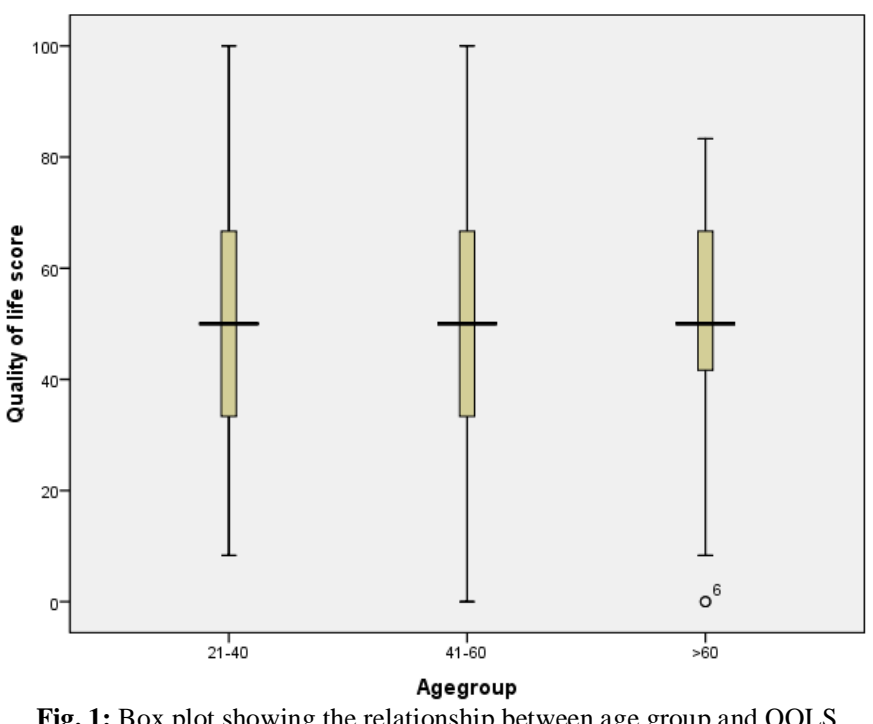

Figure 1 depicts the median and IQR of QOLS according to the age group. It was noted that though median QOLS was almost same for all age groups, a significant difference was observed between QOLS and age group of patients $(\mathrm{p}=0.011) .1$

\begin{tabular}{ccc}
\hline Age group (in years) & Median & Interquartile range (IQR) \\
\hline $21-40$ & 50 & $(33,66)$ \\
$41-60$ & 50 & $(33,66)$ \\
$>60$ & 50 & $(41,66)$ \\
\hline
\end{tabular}

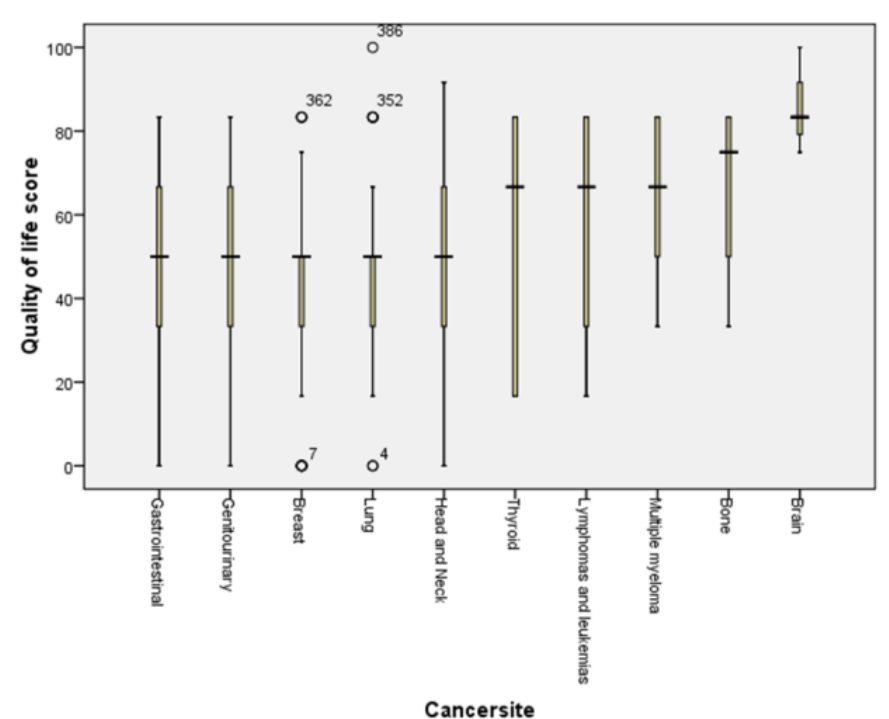

Fig. 2: Box plot showing the relationship between cancer site and QOLS

Figure 2 depicts the median and IQR of QOLS according to the site of cancer. It was observed that patients suffering from gastrointestinal, genitourinary, breast, lung, head and neck cancer had lower QOL compared to other types of cancer thus showing a significant difference $(\mathrm{p}=0.011)$. 


\begin{tabular}{ccc}
\hline Cancer site & Median & Interquartile range (IQR) \\
\hline Gastrointestinal & 50 & $(33,66)$ \\
Genitourinary & 50 & $(33,66)$ \\
Breast & 50 & $(33,50)$ \\
Lung & 50 & $(33,54)$ \\
Head and Neck & 50 & $(33,66)$ \\
Thyroid & 66.67 & $(16,83)$ \\
Lymphomas and leukemias & 66.67 & $(33,83)$ \\
Multiple myeloma & 66.67 & $(45,83)$ \\
Bone & 75 & $(41,83)$ \\
Brain & 83.33 & $(77,95)$ \\
\hline
\end{tabular}

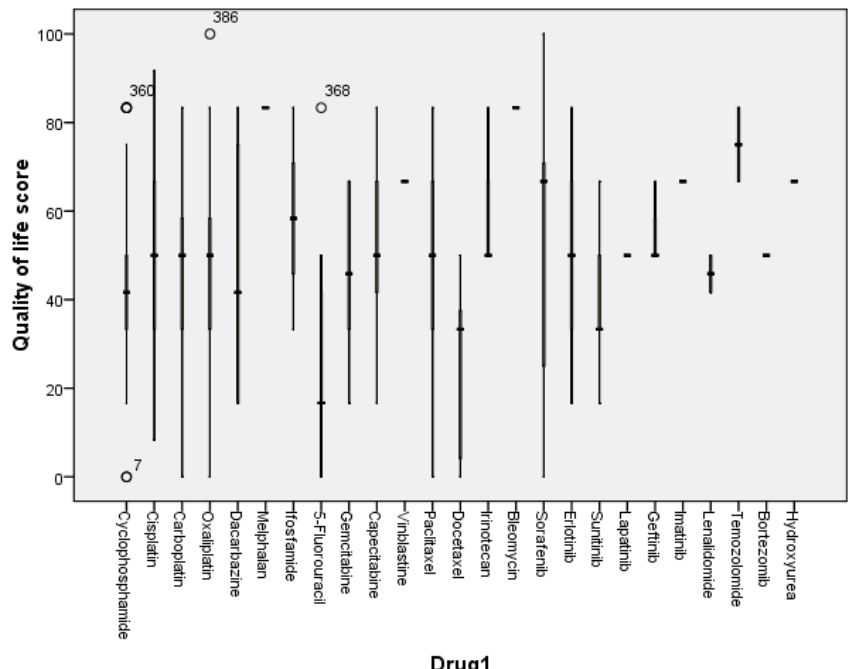

Fig. 3: Box plot showing the relationship between drug causing ADRs and QOLS

Figure 3 depicts the median and IQR of QOLS according to the drugs causing ADRs. It was observed that there was a significant difference in the median QOLS among the patients based on different drugs used for treatment of cancer $(p=0.002)$ with drugs 5-FU, docetaxel and sunitinib showing the lowest QOLS.

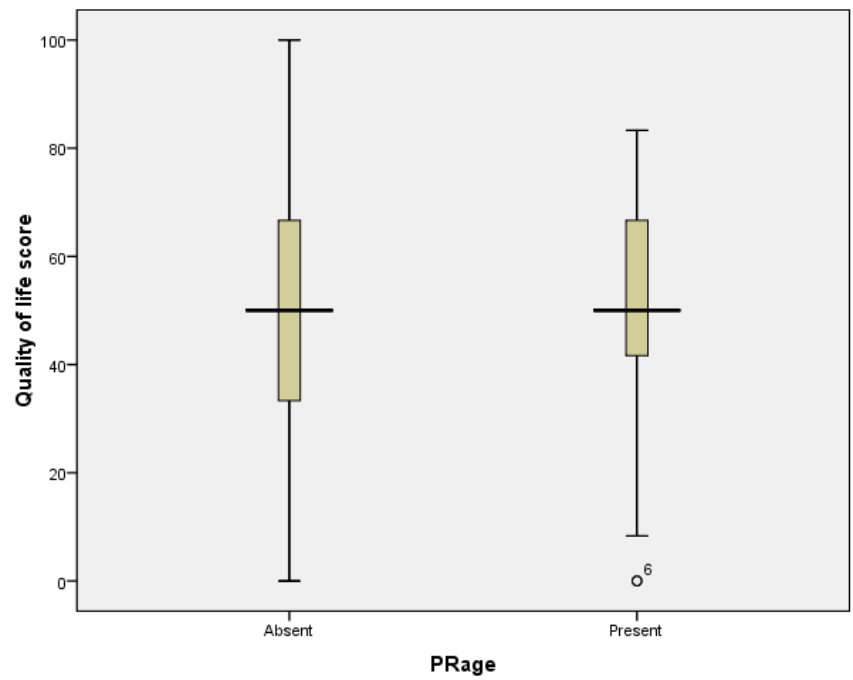

Fig. 4: Box plot showing the relationship between age as predisposing factor and QOLS

Figure 4 depicts the median and IQR of QOLS according to the age of the patient as the predisposing factor. It was observed that there was a significant difference in the median QOLS between the patients of older age ( $>60$ years) and patients with < 60 years of age $(p=0.008)$.

\begin{tabular}{ccc}
\hline $\begin{array}{c}\text { Predisposing factor } \\
\text { (Age) }\end{array}$ & Median & $\begin{array}{c}\text { Interquartile range } \\
(\text { IQR) }\end{array}$ \\
\hline Absent & 50 & $(33,66)$ \\
Present & 50 & $(41,66)$ \\
\hline
\end{tabular}

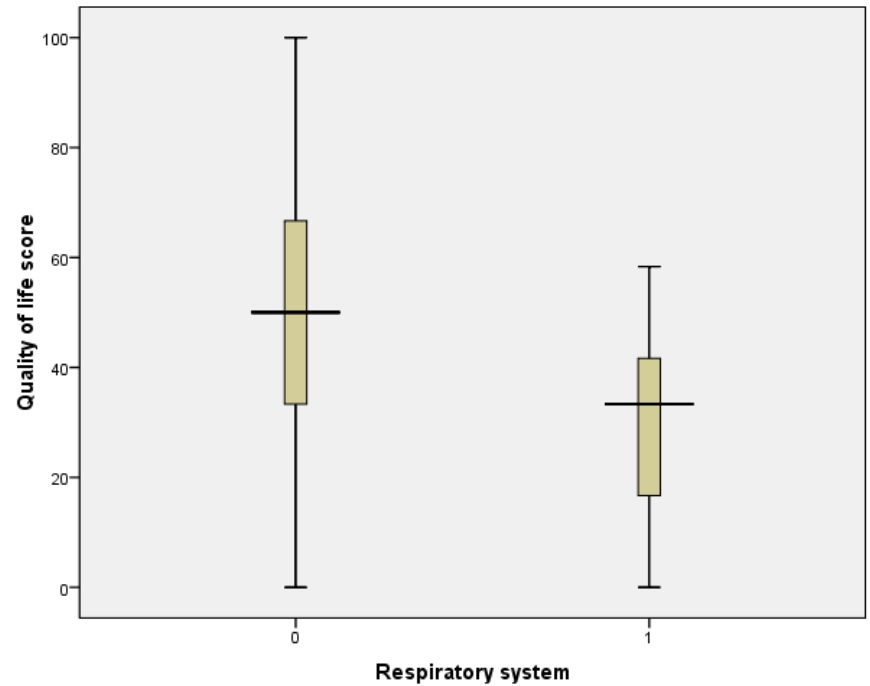

Fig. 5: Box plot showing the relationship between organ system affected (respiratory) and QOLS

Figure 5 depicts the median and IQR of QOLS according to the organ system (respiratory system) affected in the patient. It was observed that there was a significant difference in the median QOLS between the patients with and without ADRs related to respiratory system $(\mathrm{p}=0.019)$.

\begin{tabular}{ccc}
\hline $\begin{array}{c}\text { ADR related to Respiratory } \\
\text { System }\end{array}$ & Median & $\begin{array}{c}\text { Interquartile range } \\
\text { (IQR) }\end{array}$ \\
\hline 0 & 50 & $(33,66)$ \\
1 & 33.33 & $(16,45)$ \\
\hline
\end{tabular}

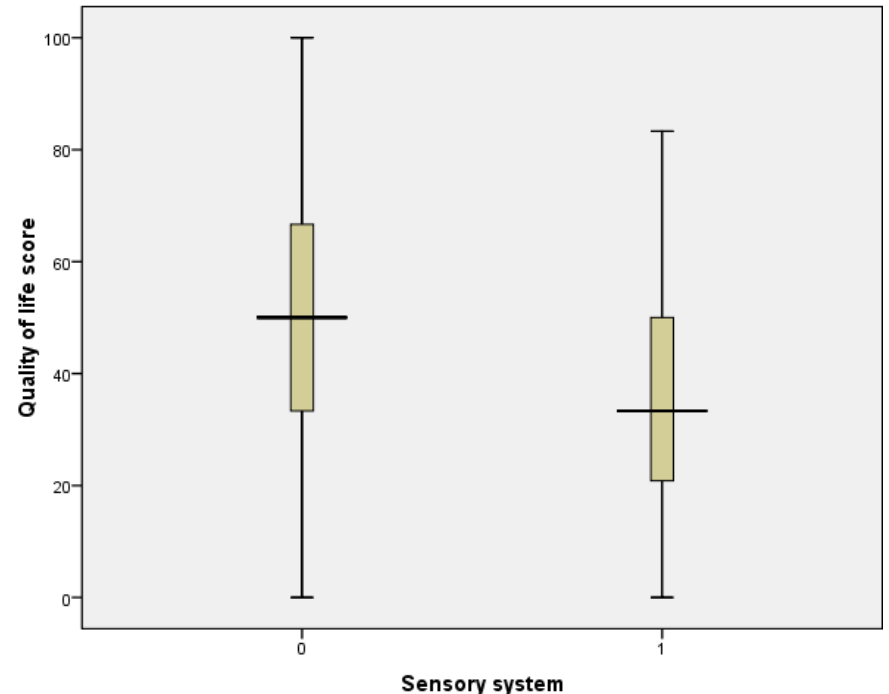

Fig. 6: Box plot showing the relationship between organ system affected (sensory) and QOLS. 
Figure 6 depicts the median and IQR of QOLS according to the organ system (sensory system) affected in the patient. It was observed that there was a significant difference in the median QOLS between the patients with and without ADRs related to sensory system $(\mathrm{p}=0.003)$.

\begin{tabular}{ccc}
\hline $\begin{array}{c}\text { ADR related to } \\
\text { Sensory System }\end{array}$ & Median & $\begin{array}{c}\text { Interquartile range } \\
\text { (IQR) }\end{array}$ \\
\hline 0 & 50 & $(33,66)$ \\
1 & 33.33 & $(18,50)$ \\
\hline
\end{tabular}

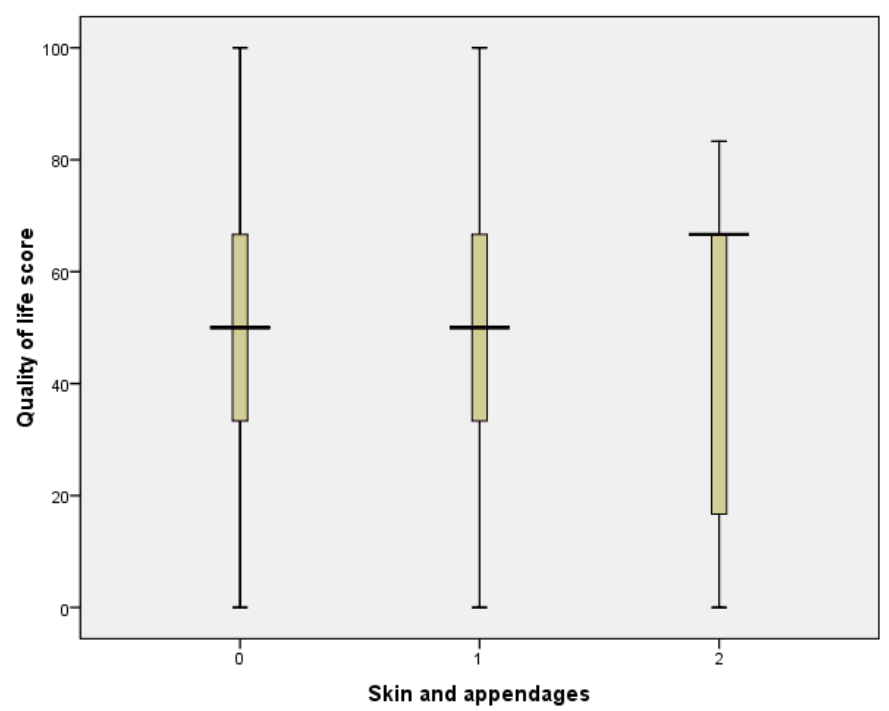

Fig. 7: Box plot showing the relationship between organ system affected (skin \& appendages) and QOLS.

Figure 7 depicts the median and IQR of QOLS according to the organ system (skin and appendages) affected in the patient. It was observed that there was a significant difference in the median QOLS between the patients with 0-2 ADRs related to skin and appendages $(\mathrm{p}=0.025)$.

\begin{tabular}{ccc}
\hline $\begin{array}{c}\text { ADR related to Skin } \\
\text { and Appendages }\end{array}$ & Median & $\begin{array}{c}\text { Interquartile range } \\
\text { (IQR) }\end{array}$ \\
\hline 0 & 50 & $(33,66)$ \\
1 & 50 & $(33,66)$ \\
2 & 66.67 & $(16,75)$ \\
\hline
\end{tabular}

Predictor model for quality of life scores in cancer patients on chemotherapy

Table 3: Quality of life predictor model.

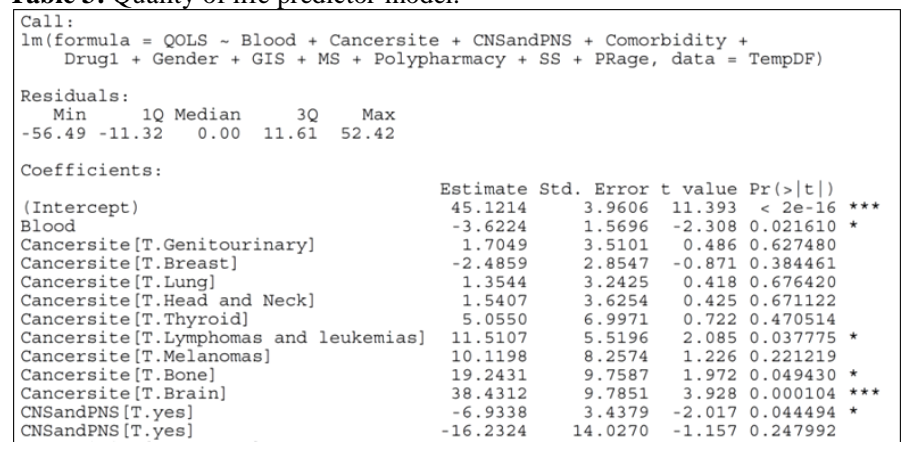

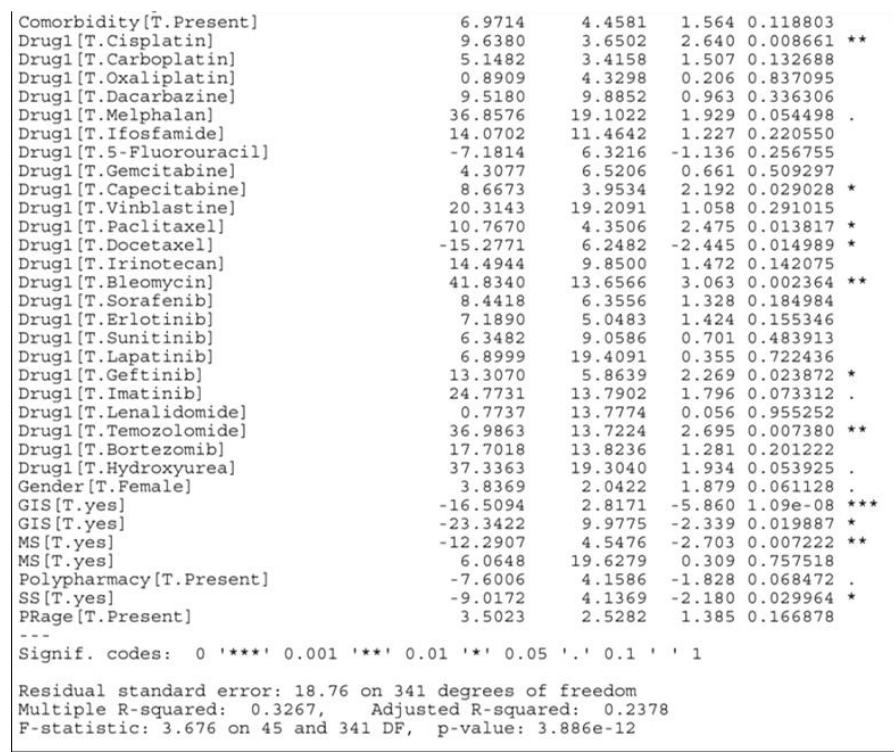

\section{Model is as follows:}

Quality of life score

$=45.12-(3.62 \times$ Blood $)+(11.51 \times$ lymphomas and leukemias $)$

$+(19.24 \times$ bone $)+(38.43 \times$ brain $)$

$-(6.93 \times$ CNS and PNS $)+(9.63 \times$ cisplatin $)$

$+(8.66 \times$ capecitabine $)+(10.76 \times$ paclitaxel $)$

$+(41.83 \times$ bleomycin $)+(13.30 \times$ geftinib $)$

$+(36.98 \times$ temozolomide $)$

$-(16.50 \times$ gastrointestinal system $)$

$-(12.29 \times$ musculoskeletal system $)$

$-(9.01 \times$ sensory system $)$

The Coefficient of determination $\mathrm{R}$-square $\left(\mathrm{R}^{2}\right)$ was found to be 0.3267 indicating that $32.67 \%$ of the variation in the 'quality of life score' is explained by the independent variables included in the model.

The $\mathrm{F}_{(45,341)}=3.67, \mathrm{p}<0.001$ indicating the overall significance of the regression model.

\section{DISCUSSION}

Global health status/QOL in cancer patients receiving chemotherapy in our study was found to be average for $72.35 \%$ patients with a mean of $47.17 \pm 21.48$. This is similar to a study conducted by Cheng et al with a mean of $54.3 \pm 28.7$ and Abdollahzadeh et al with a mean of $64.1 \pm 18.8$ (Cheng et al., I2010; Abdollahzadeh et al., I2012). However, it is in contrast to the study conducted by Nicolussi $e t$ al with a mean of $74.91 \pm 23.36$ (Nicolussi et al., 12014).

In our study, a significant difference was observed between QOLS and age group of the patients. Similar findings were observed in a study where head and neck cancer patients aged below 65 years had significantly better HR-QOL than their counterparts (Hammerlid and Taft, 2001). One of the study also showed that younger ages were significant predictors of poor $\mathrm{QOL}$ during chemotherapy (Le et al., I2004). Although, a study reported that female sex was associated with worser HR-QOL, no significant differences were observed in our study (Graeff et al., 
I2000). However, a study conducted in Iran also showed that there is no correlation between the QOL and gender of the patient (Heydarnejad et al., I2011).

A significant difference was observed between QOLS and site of cancer in our study which is similar to the findings by Wan Leung et al (Wan Leung et al., I2011). In our study, a significant difference was found in QOLS based on the drugs used in treatment of cancer with drugs like 5-FU, docetaxel and sunitinib showing the lowest QOLS. A study by Le at al showed that the use of topotecan, cisplatinum and etoposide were significant predictors of poor quality of life during chemotherapy (Le et al., I2004).

In our study, QOLS of patients with a total cost due to ADRs of more than Rs.50000 was found to be lower when compared to patients with a lesser total cost (< Rs.50000). Hence, it indicates that the economic burden has a negative impact on the QOL of the patients though it was not found to be statistically significant $(\mathrm{p}=0.335)$. A study by Safaee et al reported that various ADRs caused due to cancer chemotherapy showed a significant impact on the QOL and financial difficulties of the patient (Safaee et al., I2008).

Predictor model for QOLS was developed with the collected data. In this model, the coefficient of determination $\mathrm{R}$ square $\left(R^{2}\right)$ was found to be 0.3267 indicating that $32.67 \%$ of the variation in the 'quality of life score' can be explained by the independent variables included in the model. The $\mathrm{F}_{(45,341)}=3.67$, $\mathrm{p}<0.001$ indicating the overall significance of the regression model. The model included several independent variables as predictors which consisted of ADRs affecting the organ systems like blood, CNS, PNS, GIS, MS and sensory system, site of cancer like lymphomas and leukemias, bone and brain, drugs used in treatment of cancer like cisplatin, capecitabine, paclitaxel, docetaxel, bleomycin, geftinib and temozolomide. Among them, ADRs affecting GIS alone explained $16.50 \%$ of variation in the QOLS negatively.

One of the limitation of the study is that the predictor model developed were not validated due to unavailability of the adequate sample. Therefore, one of the major challenge in this area of research is focusing on developing the predictor models which requires large sample size. Since time is a constraint, long-term research is required to draw authentic and reliable conclusions.

\section{CONCLUSION}

The present study showed significant differences in QOLS based on the age group, site of cancer, drugs used in treatment of cancer, age as a predisposing factor and organ system affected due to ADRs (respiratory system, sensory system, skin and appendages). The predictor model for QOLS explained $32.67 \%$ of variation in the QOLS. Among the various predictors, ADRs affecting gastrointestinal system explained $16.50 \%$ of variation in the QOLS negatively. Thus, there are various predictors that can help to assess the QOL in cancer patients which can further serve as a guide to implement timely interventions to improve patients QOL.

\section{ACKNOWLEDGEMENT}

Authors would like to acknowledge all the patients who participated in the study and staff members, postgraduates and nurses of the Department of Radiotherapy and Oncology, Kasturba Medical College, Manipal, India for their consistent help and support throughout the study period.

Conflict of Interest: None

\section{REFERENCES}

Aaronson N, Ahmedzai S, Bergman B, Bullinger M, Cull A, Duez NJ, et al. The European Organization for Research and Treatment of Cancer QLQ-C30: A quality-of-life instrument for use in international clinical trials in oncology. J Natl Cancer Inst, 1993; 85(5): 365-376.

Abdollahzadeh F, Sadat Aghahossini S, Rahmani A, Asvadi Kermani I. Quality of life in cancer patients and its related factors. Scand J Caring Sci, 2012; 1(2):109-114.

Chaukar DA, Das AK, Deshpande MS, Pai PS, Pathak KA, Chaturvedi P, Kakade AC, Hawaldar RW, D'Cruz AK : Quality of life of head and neck cancer patient. Indian Journal of Cancer, 2005 (Oct-Dec); 42(4): 178-184.

Cheng JX, Liu BL, Zhang X, Lin W, Zhang YQ, Liu WP, et al. Health-related quality of life in glioma patients in China. BMC Cancer, 2010; 10(1): 305-312.

Fayers PM, Aaronson NK, Bjordal K, Groenvold M, Curran D, Bottomley A on behalf of the EORTC Quality of Life Group. The EORTC QLQ-C30 Scoring Manual (3rd Edition): European Organisation for Research and Treatment of Cancer, Brussels, 2001.

Graeff de A, Leeuw de JRJ, Ros WJ, Hordijk GJ, Blijham GH, Winnubst JA. Long-term quality of life of patients with head and neck cancer. The Laryngoscope, 2000; 110(1): 98-106.

Guyatt G, Feeny DH, Patrick DL. Measuring health-related quality of life. Ann Inter Med, 1993;118:622-629.

Hammerlid E, Taft C. Health-related quality of life in long-term head and neck cancer survivors: a comparison with general population norms. Br J Cancer, 2001; 84(2):149-156.

Hartwig SC, Siegel J, Schneider PJ. Preventability and severity assessment in reporting adverse drug reactions. Am J Hosp Pharm, 1992; 49(9): 2229-2232.

Heydarnejad M, Hassanpour DA, Solati DK. Factors affecting quality of life in cancer patients undergoing chemotherapy. Afr Health Sci, 2011; 11(2): 266-270.

Johnson JA, Bootman JL. Drug-related morbidity mortality: a cost-of-illness model. Arch Intern Med, 1995; 155(18): 1949-1956.

Le T, Leis A, Pahwa P, Wright K, Ali K, Reeder B, et al. Quality of life evaluations in patients with ovarian cancer during chemotherapy treatment. Gynecol Oncol, 2004; 92(3): 839-844.

Lundkvist J, Jonsson B. Pharmacoeconomics of adverse drug reactions. Fundam Clin Pharmacol, 2004; 18(3): 275-280.

Nicolussi AC, Sawada NO, Cardozo FMC, Andrade V, Paula JM. Health-related quality of life of cancer patients undergoing chemotherapy. Rev Rene, 2014; 15(1):132-140.

Project Proposal September 2012. State Health Systems Resource Centre National Rural Health Mission. Department of Health 
and Family Welfare, Government of Punjab. Available from: pbhealth.gov.in/Final\%20State\%20 Proposal.pdf

Safaee A, Moghimi-Dehkordi B, Zeighami B, Tabatabaee H, Pourhoseingholi M. Predictors of quality of life in breast cancer patients under chemotherapy. Indian J Cancer 2008; 45(3):107-111.

Schumock GT, Thornton JP. Focusing on the preventability of adverse drug reactions. Hosp Pharm 1992; 27(6): 538.

Wang Leung S, Lee TF, Chien CY, Chao PJ, Tsai WL, Fang FM . Health-related Quality of life in 640 head and neck cancer survivors after radiotherapy using EORTC QLQ-C30 and QLQ-H\&N35 questionnaires. BMC Cancer 2011; 11:128-137.

WHO QOL: Measuring Quality of Life. World Health Organization 1997.

World cancer report 2014.

\section{How to cite this article:}

Khandelwal S, Bairy KL, Vidyasagar MS, Kamath A, Gonsalves J, Chogtu B. Development of a Predictor Model for Quality of Life in Cancer Patients with Adverse Drug Reactions due to Cancer Chemotherapy. J App Pharm Sci, 2016; 6 (05): 022-028. 